\title{
Detection of foreign objects in milk using an ultrasonic system
}

\author{
Mohd Taufiq Mohd Khairi, Sallehuddin Ibrahim, Mohd Amri Md Yunus, Ahmad Ridhwan Wahap \\ Control and Mechatronics Engineering Division, Universiti Teknologi Malaysia, Malaysia
}

\begin{tabular}{l}
\hline Article Info \\
\hline Article history: \\
Received Dec 19, 2018 \\
Revised Mar 21, 2019 \\
Accepted Apr 15, 2019 \\
\hline
\end{tabular}

\section{Keywords:}

Attenuation

Foreign objects

Milk

Sensor

Ultrasonic

\begin{abstract}
This paper presents the utilization of an ultrasonic sensing system to detect foreign objects in milk. The advantage of an ultrasonic system is that it is low cost and it can detect a wide range of materials. A foreign body is any contaminated object found in food. Because of the scale of multifarious food processing levels and distribution, the utilization of the food product are sometimes difficult to control, which will inevitably lead to some complaints by consumers. Milk is widely consumed in the world as it is considered as a healthy drink due to it is high nutrients levels. However, from time to time cases of milk contamination are reported. In this paper, the relationship between the foreign bodies in terms of their dimensions and the resultant amplitude are presented. Mathematical modelling were carried out based on two ultrasonic parameters i.e. acoustic impedance and wave amplitude utilizing several types of foreign bodies with different dimensions. Three types of foreign bodies which are steel, rubber and air were investigated to determine the voltage amplitude detected by the ultrasonic receiver when the foreign bodies obstructed the ultrasonic wave propagation path. The diameters of foreign bodies were in the range from $4 \mathrm{~mm}$ to 11 $\mathrm{mm}$. The results showed good correlations between the receiver voltage and the size of foreign bodies with correlation coefficients greater than 0.95 . Each foreign body also demonstrated different voltage amplitudes when several sizes of the foreign bodies were tested which showed the ability of the system to distinguish the size of each foreign body.
\end{abstract}

Copyright (C) 2019 Institute of Advanced Engineering and Science. All rights reserved.

Corresponding Author:

Sallehuddin Ibrahim,

Control and Mechatronics Engineering Division,

UniversitTeknologi Malaysia,

Skudai, Johor, 81300 Malaysia.

Email: salleh@fke.utm.my

\section{INTRODUCTION}

Milk contains a variety of vital compositions for human beings such as carbohydrate that provide energy to the body. It also provides a source of protein that can develop human muscle to be more healthy and strong. Moreover, milk is also loaded with calcium sources which can strengthen bones and protect against tooth decay. Dairy milk is exposed to be contaminated with various forms such as chemical, biological and physical substances [1]. It is said to be polluted by chemicals substance when the chemicals liquid exists during the manufacturing process such as oil from milk processing machines accidently spills into the milk tank. Milk is sometimes contaminated with biological materials such as E. coli and Salmonella bacteria via poor milking practices, soiled hands and soiled equipment. Contamination through physical substance occurs when foreign objects such as hair, steel, glass, plastic and rubber fragments accidently included in the processing machine and packaging container.

The existence of foreign objects in the milk product is a cause of concern ascan endanger human health [2]. The colour of milk is not transparent and it is produced in a variety of flavours such as chocolate, strawberry, full cream and fresh milk. Therefore, it is difficult to see by the naked eye if there is any foreign object in the milk. If lucky, we will be able to distinguish the foreign body when it floats on the surface of the 
milk when the milk is poured into the cup. In addition, the knocking noise also can be heard when the foreign body hitting the cup when pouring process. The consumers are exposed to risk if the milk is drink directly from the milk carton or using a straw. This paper presents the application of ultrasonic sensor to detect the foreign body in milk cartons. In detecting foreign objects, an ultrasonic system has the advantages of being inexpensive and non-intrusive. As such the objects of interest are not damaged. Ultrasonic sensors are widely applied in food industry since it offers a non-destructive way to inspect the product [3, 4]. Ultrasonic has been successfully been applied for freezing, cavitation, emulsification and thermosonication for many types of food products [5-7]. Several investigationson foreign body detection using ultrasonic sensor had been carried out as reported by Correia et al [8], Zhao et al [9], Pallav et al [10],Leemans and Destain[11], Tantray et al [12] and Polat et al [13], Mcclements [14],Hassler and Homayoon [15], Le Coz et al [16],Iuliano [17], Liu et al [18], Liaw et al [19], Makinde et al [20], Holmes et al [21], Melo et al [22], Khan et al [23], Prabhakar et al [24], Rodrigues et al [25], Franchini et al [26], Pandey [27], Aftab et al [28], Gounder and Tan [29], Sadaka et al [30], Fasina et al [31], Khan et al [32], Mitev et al [33], Roux et al [34], Nakib et al [35], Rathore [36], Singleton et al [37], Mahesh et al [38], Ezenwa [39], Natung [40] and Mustapha [41], In this paper, two common foreign bodies materials e.g. steel and rubber with different sizes were used to investigate the sensor voltage and voltage loss at the ultrasonic receiver. The mathematical modelling was studied using two parameters which commonly applied in ultrasonic measurement which is acoustic impedance and amplitude wave. Air medium was used to compare with the metal and the rubber materials since the air has the lowest acoustic impedance which is $0.00041 \times 10^{6} \mathrm{~kg} / \mathrm{m}^{2} \mathrm{~s}$.

\section{MATHEMATICAL MODELLING}

This section consists of two modelling of parameters that related to the ultrasonic acoustic properties which are acoustic impedance and amplitude wave. Some assumptions have been used in the modelling and experiment. First, the round shape is selected as a foreign body's shape. Next assumption is the energy losses between ultrasonic transducer and couplant is assumed to be zero.

The acoustic impedance is another parameter that must be considered in the ultrasonic interaction concept. The acoustic impedance is expressed as:

$$
Z=\rho c
$$

where $\rho$ is the density of the material $\left(\mathrm{kg} / \mathrm{m}^{3}\right)$ and $c$ is the sound velocity of the material $(\mathrm{m} / \mathrm{s})$. The transmission and reflection coefficients of a wave are calculated based on the following equations:

$$
\begin{aligned}
& \text { Reflection coefficient, } R=\left(\frac{Z_{2}-Z_{1}}{Z_{2}+Z_{1}}\right)^{2} \\
& \text { Transmission coefficient, } T=\frac{4 Z_{1} Z_{2}}{\left(Z_{1}+Z_{2}\right)^{2}}
\end{aligned}
$$

where $Z_{1}$ and $Z_{2}$ are the acoustic impedances for material 1 and material 2 respectively. The modelling for several materials such as milk carton and foreign body material are investigated. The values of density, speed of sound and acoustic impedance for the materials are tabulated in Table 1 and Figure 1 shows the interlayers of materials regarding the acoustic impedance of the ultrasonic wave. Milk carton consists of three different layers which is polyethylene, soft wood and hard wood. The thickness of each layer has a range from $0.1 \mathrm{~mm}$ to $0.3 \mathrm{~mm}$.

Table 1. The Values of Density, Speed of Sound and Acoustic Impedance for Materials [14]

\begin{tabular}{cccc}
\hline Material & Density, $\rho\left(\mathrm{kg} / \mathrm{m}^{3}\right)$ & Speed of sound, $c(\mathrm{~m} / \mathrm{s})$ & Acoustic Impedance, $Z\left(\times 10^{6} \mathrm{~kg} / \mathrm{m}^{2} \mathrm{~s}\right)$ \\
\hline Polyethylene & 900 & 1950 & 1.76 \\
Wood (soft) & 450 & 3600 & 1.62 \\
Wood (hard) & 850 & 3850 & 3.27 \\
Milk & 1037 & 1548 & 1.61 \\
Rubber & 1200 & 1600 & 1.92 \\
Steel & 7850 & 5790 & 45.45 \\
Air & 1.2 & 343 & 0.00041 \\
\hline
\end{tabular}




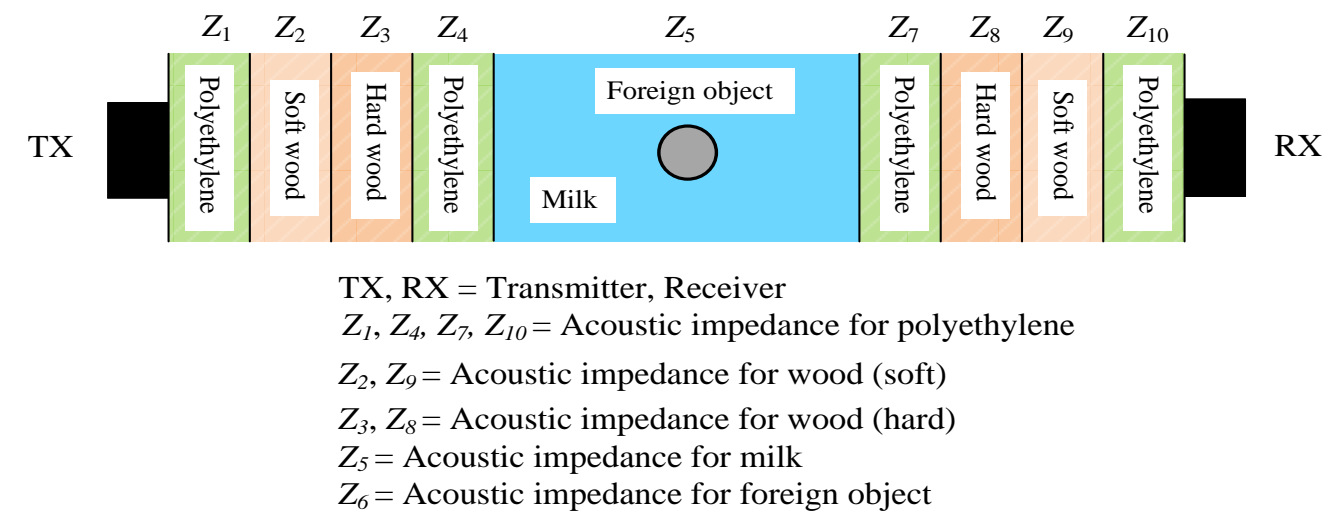

Figure 1. The interlayers materials regarding the acoustic impedance of the ultrasonic wave

The transmission and reflection coefficient at each boundary and material were determined using (2) and (3) and the results are presented in Table 2. In boundary 1 until boundary 4, the ultrasonic wave experienced more transmission than reflection by $98.72 \%, 87.89 \%, 91.20 \%$ and $99.70 \%$ respectively. Thus, the wave energy does not significantly decrease during propagating in these boundaries. However, the wave experienced more reflection by $99.90 \%$ and $86.80 \%$ when the air and steel are designated as a foreign body. On the other hand, the ultrasonic wave just shows $0.77 \%$ of reflection when the rubber is used as foreign body.

Table 2. The Reflection and Transmission Coefficients in Percentages

\begin{tabular}{cccc}
\hline Boundary & Condition & Reflection (\%) & Transmission (\%) \\
\hline 1 & Polyethylene to wood (soft) & 1.28 & 98.72 \\
2 & Wood (soft) to wood (hard) & 12.11 & 87.89 \\
3 & Wood (hard) to polyethylene & 8.80 & 91.20 \\
4 & Polyethylene to milk & 0.30 & 99.70 \\
5 & Milk to polyethylene & 0.30 & 99.70 \\
$6(\mathrm{i})$ & Milk to foreign body (air) & 99.80 & 0.20 \\
$6(\mathrm{ii})$ & Milk to foreign body (rubber) & 0.69 & 99.31 \\
$6(\mathrm{iii})$ & Milk to foreign body (steel) & 87.10 & 12.90 \\
7 & Polyethylene to wood (hard) & 9.20 & 90.80 \\
8 & Wood (hard) to wood (soft) & 11.23 & 88.77 \\
9 & Wood (soft) to polyethylene & 0.15 & 99.85 \\
\hline
\end{tabular}

The analysis of the amplitude wave is a simple approach to determine whether the milk contains any foreign body or not. The transmitted wave has a certain wave energy level that should be detected by a receiver. The foreign body size has influenced the level of amplitude wave. The larger size of the foreign body led to more reduction in the amplitude due to the wave being blocked from propagating to the receiver. The level of voltage at the receiver can determine the correlation between the size and amplitude wave as illustrated in Figure 2. The size of ultrasonic sensor used in this study is 13 millimeter $(\mathrm{mm})$ and the transmitter voltage is 4.8 Volt (V). The equation for the receiver voltage equation is written as [42]:

$$
\begin{aligned}
& V_{R}=V_{T}-V_{d} \\
& \frac{V_{R}}{V_{T}}=\frac{d}{13} \\
& V_{R}=d / 13 \times V_{T}
\end{aligned}
$$

As shown in (6) is inserted into (4) to get:

$$
V_{R}=V_{T}-\left[d / 13 \times V_{T}\right]
$$




$$
V_{R}=4.8-[d / 13 \times 4.8]
$$

where $V_{R}$ is the receiver voltage, $V_{T}$ is the transmitter voltage, $V_{d}$ is the voltage loss when there is a foreign body between the transmitter and the receiver.

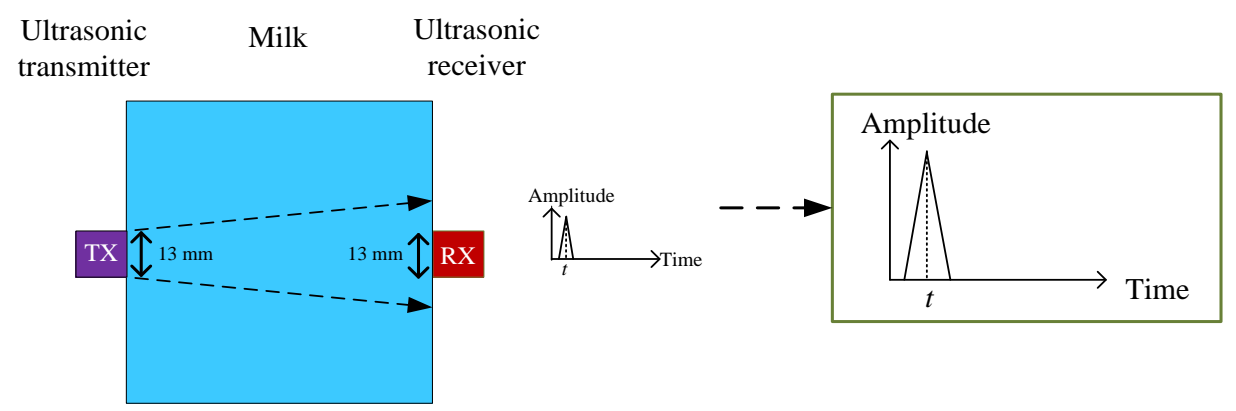

(a)

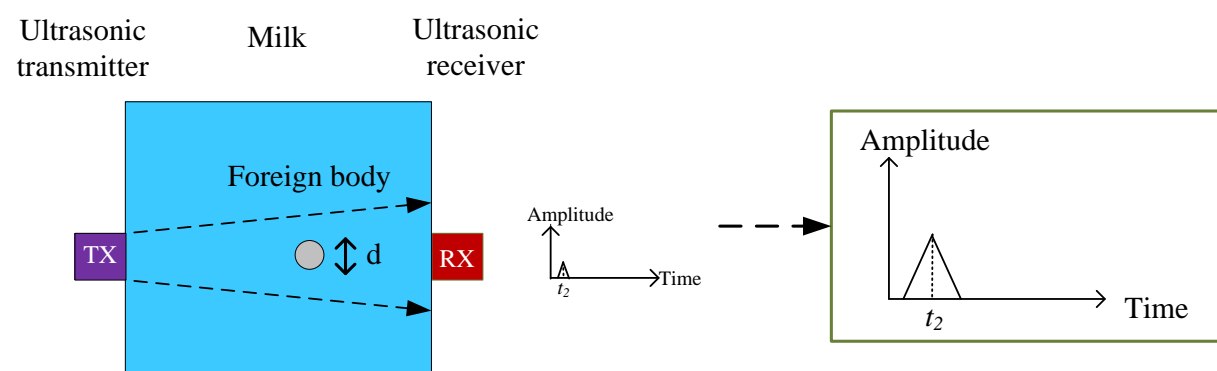

(b)

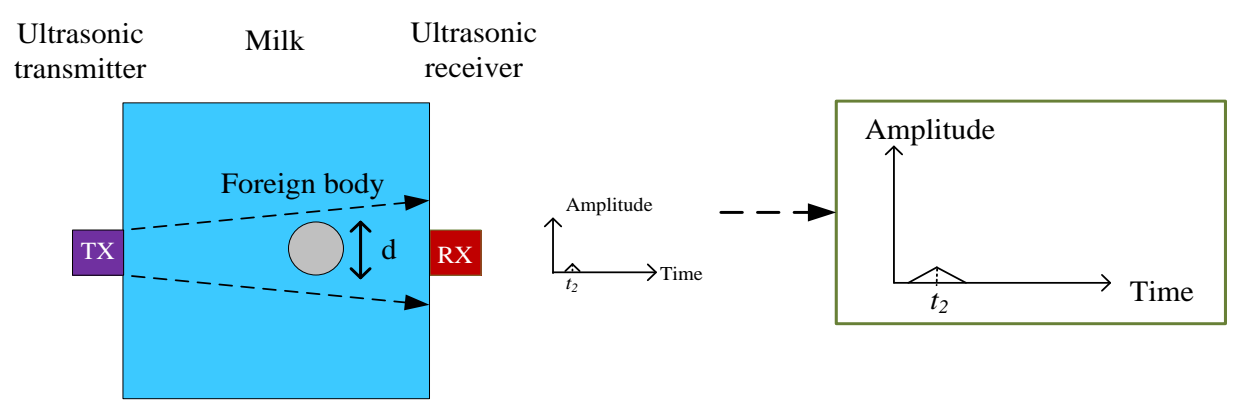

(c)

Figure 2. Predicted amplitudes for different sizes of foreign bodies

\section{EXPERIMENTAL SETUP}

Two ultrasonic sensors model MCUSD13A300B09RS developed by Multicomp were used as transcceivers. The sensors have a center frequency of 300 kilohertz $(\mathrm{kHz})$, diameter of $13 \mathrm{~mm}$ and the length is $9 \mathrm{~mm}$. It has $10^{\circ}$ of angle beam and the sensor is covered by aluminum case. The transmitter and receiver circuit were driven by 12 Volt $(\mathrm{V})$ from direct current power supply and a port from Peripheral Interface Controller (PIC) microcontroller model PIC18F4520 was used to generate the pulse signal to transmitter circuit. The wave signal was evaluated and measured using an oscilloscope. The transmitter and the receiver were placed outside of a milk carton which the carton has a cross sectional size of $7.3 \mathrm{~mm} \times 7.4 \mathrm{~mm}$. The experiment was conducted using pasteurized chocolate milk manufactured by Dutch Lady under the condition of $24^{\circ} \mathrm{C}$ for milk and room temperature. The experimental setup for the ultrasonic measurement is illustrated as in Figure 3. 


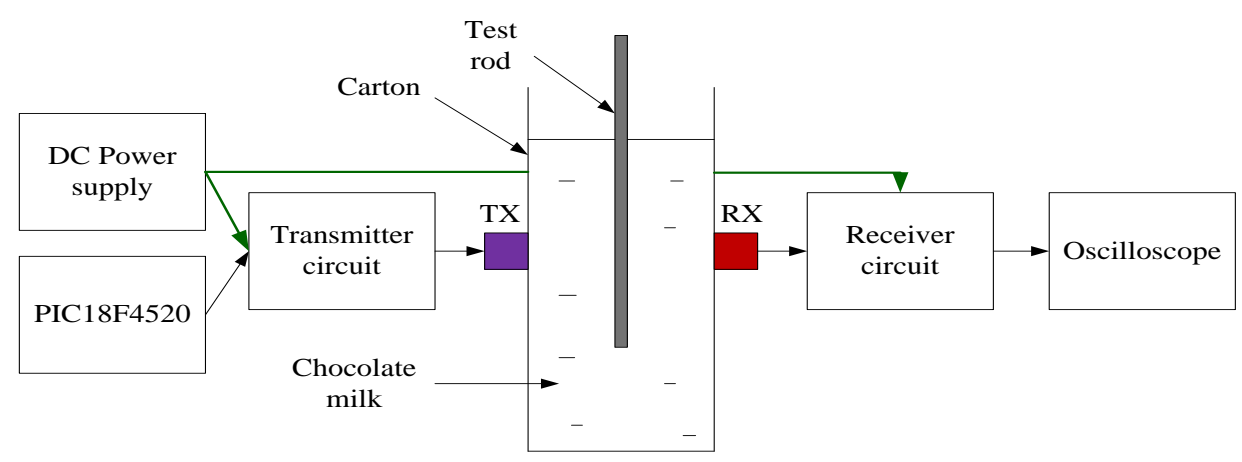

Figure 3. The experimental setup for ultrasonic measurement

\section{RESULTS AND DISCUSSION}

This section comprises the experimental results and the discussion. In the experimental work, two types of voltage were investigated which are the receiver voltage and the voltage loss. Both theoretical and experimental voltages were calculated based on (6) and (8) for determining the correlation between three different materials of foreign bodies; air, steel and rubber. Several sizes of rods for each material had been used where the diameters of the rods were from $4 \mathrm{~mm}$ to $11 \mathrm{~mm}$. The example of waveforms for the nonexistence and existence of foreign object are shown in Figure 4(a) and Figure 4(b), respectively where a steel rod with diameter of $7 \mathrm{~mm}$ was used as the foreign object.

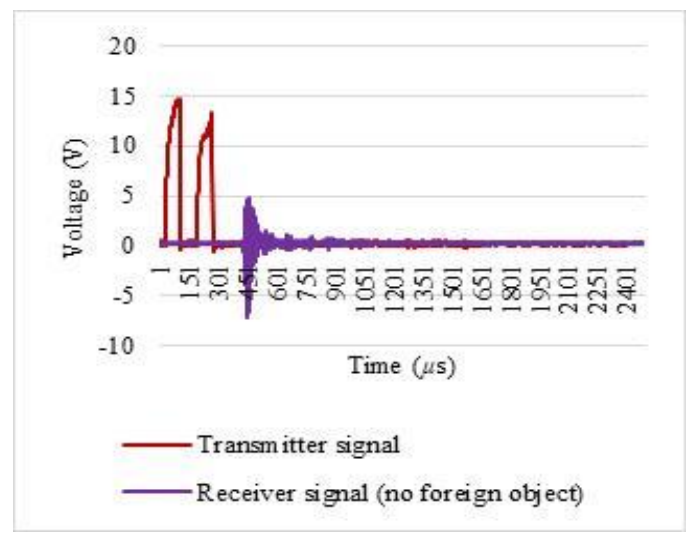

(a)

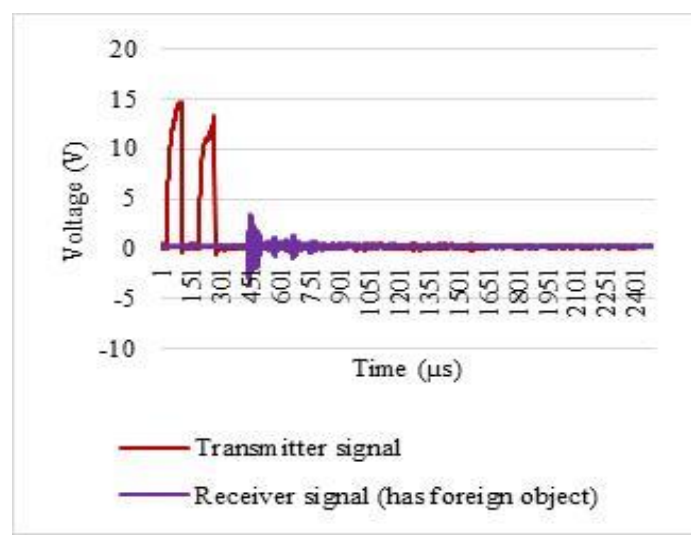

(b)

Figure 4. The ultrasonic waveform (a) Non-existence of foreign object (b) Existence of foreign object

The correlation between the size and foreign body's materials were analyzed using linear regression analysis. A linear regression line has an equation of the form $Y=a+b X$, where $X$ is the explanatory variable and $Y$ is the dependent variable. The value of $a, b$ and correlation coefficient $(r)$ is calculated using (9), (10) and (11), respectively where $x$ and $y$ are plenty of data, $n$ is total sample data, $\bar{x}$ is mean of $x$ data and $\bar{y}$ is mean of $y$ data. The results of the receiver voltage and voltage loss were presented in Table 3 and plotted graphically in Figure 5 and Figure 6. The linear regression equation and the value of regression coefficient for receiver voltage and voltage loss are presented in Table 4 and Table 5.

$$
\begin{aligned}
& a=\frac{\left(\sum y\right)\left(\sum x^{2}\right)-\left(\sum x\right)(x y)}{n\left(\sum x^{2}\right)-\left(\sum x\right)^{2}} \\
& b=\frac{n\left(\sum x y\right)-\left(\sum x\right)(y)}{n\left(\sum x^{2}\right)-\left(\sum x\right)^{2}} \\
& r=\frac{\sum_{i=1}^{N}\left(x_{i}-\bar{x}_{i}\right)\left(y_{i}-\bar{y}_{i}\right)}{\sqrt{\left(\sum_{i=1}^{N}\left(x_{i}-\bar{x}_{i}\right)^{2}\right)\left(\sum_{i=1}^{N}\left(y_{i}-\bar{y}_{i}\right)^{2}\right)}}
\end{aligned}
$$


Table 3. Theoretical and Experimental Results

\begin{tabular}{|c|c|c|c|c|c|c|c|c|}
\hline \multirow{3}{*}{$\begin{array}{l}\text { Diameter, } d \\
(\mathrm{~mm})\end{array}$} & \multirow{2}{*}{\multicolumn{2}{|c|}{$\begin{array}{l}\text { Theoretical } \\
\text { Predicted }\end{array}$}} & \multirow{2}{*}{\multicolumn{2}{|c|}{ Air }} & \multirow{2}{*}{\multicolumn{2}{|c|}{$\begin{array}{l}\text { Experimental } \\
\text { Steel }\end{array}$}} & \multirow{2}{*}{\multicolumn{2}{|c|}{ Rubber }} \\
\hline & & & & & & & & \\
\hline & $\begin{array}{c}\text { Receiver } \\
\text { voltage, } V_{R} \\
(\mathrm{~V})\end{array}$ & $\begin{array}{l}\text { Voltage loss } \\
\text { (V) }\end{array}$ & $\begin{array}{c}\text { Receiver } \\
\text { voltage, } \\
V_{R}(\mathrm{~V}) \\
\end{array}$ & $\begin{array}{l}\text { Voltage } \\
\text { loss (V) }\end{array}$ & $\begin{array}{l}\text { Receiver } \\
\text { voltage, } V_{R} \\
\text { (V) }\end{array}$ & $\begin{array}{l}\text { Voltage } \\
\text { loss (V) }\end{array}$ & $\begin{array}{l}\text { Receiver } \\
\text { voltage, } V_{R} \\
\text { (V) }\end{array}$ & $\begin{array}{l}\text { Voltage } \\
\text { loss (V) }\end{array}$ \\
\hline 11 & 0.738 & 4.062 & 0.800 & 4.000 & 2.000 & 2.800 & 3.000 & 1.800 \\
\hline 10 & 1.108 & 3.692 & 1.400 & 3.400 & 2.300 & 2.500 & 3.200 & 1.600 \\
\hline 7 & 2.215 & 2.585 & 2.200 & 2.600 & 3.400 & 1.400 & 3.400 & 1.400 \\
\hline 5 & 2.954 & 1.846 & 3.400 & 1.400 & 3.800 & 1.000 & 4.000 & 0.800 \\
\hline 4 & 3.323 & 1.477 & 3.600 & 1.200 & 4.000 & 0.800 & 4.300 & 0.500 \\
\hline
\end{tabular}

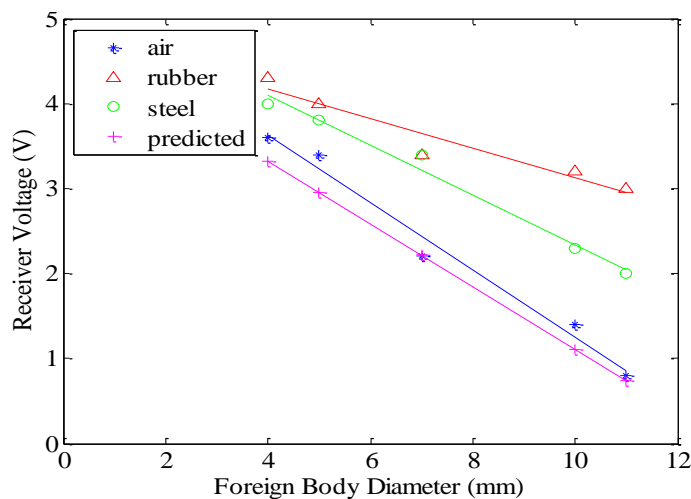

Figure 5. The correlation graph between foreign body diameter and receiver voltage

Table 4. The Regression Equation and Correlation Coefficient for Receiver Voltage

\begin{tabular}{ccc}
\hline Material & Regression equation & $\begin{array}{c}\text { Correlation } \\
\text { coefficient, } r\end{array}$ \\
\hline Ideal & $y=-0.3693 x+4.8001$ & 1 \\
Air & $y=-0.3968 x+5.2161$ & 0.9906 \\
Steel & $y=-0.293 x+5.2683$ & 0.9928 \\
Rubber & $y=-0.1737 x+4.8651$ & 0.9637 \\
\hline
\end{tabular}

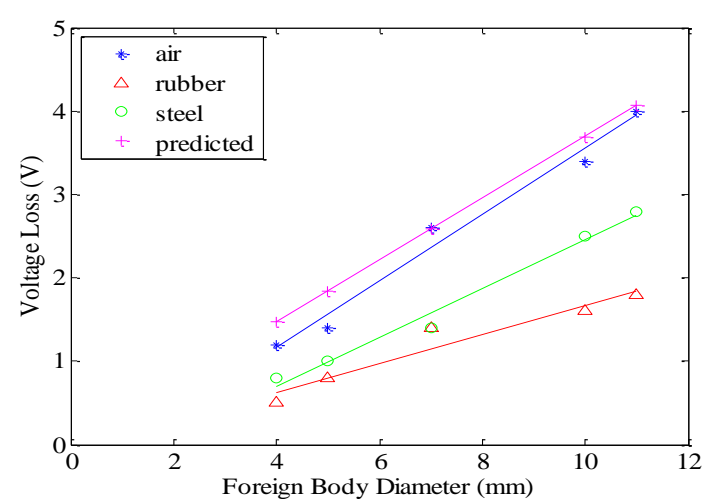

Figure 6. The correlation graph between foreign body diameter and voltage loss

Table 5. The Regression Equation and Correlation

\begin{tabular}{ccc}
\multicolumn{3}{c}{ Coefficient for Voltage Loss } \\
\hline Material & Regression equation & $\begin{array}{c}\text { Correlation } \\
\text { coefficient, } r\end{array}$ \\
\hline Ideal & $y=0.3693 x-7 \mathrm{E}-05$ & 1 \\
Air & $y=0.3968 x-0.4161$ & 0.9906 \\
Steel & $y=0.293 x-0.4683$ & 0.9928 \\
Rubber & $y=0.1737 x-0.0651$ & 0.9637 \\
\hline
\end{tabular}

\subsection{Discussion}

Both receiver voltage and voltage loss showed the same correlation coefficient for all foreign bodies materials. The level of receiver voltage is decreased when larger diameter of foreign body is placed between the transmitter and receiver sensor. Each material also shown the different level of receiver voltage due to the different acoustic impedances value. Steel material showed the lower voltage compare to the rubber materials for all diameter size. This situation verified that the wave has reflected away with $86.80 \%$ compared to $13.20 \%$ for transmission (as calculated in section 2.1) when it propagating through the steel material. Hence, the amplitude of wave energy is decreased when it reached at receiver sensor. The air medium had been tested as a foreign body to observe and compare the different consequence between steel and rubber. As expected, the air medium showed the minimum receiver voltage and the maximum voltage loss for all diameter of foreign body. The result has obeyed the theoretical calculation as studies in section 2.1 where the air medium has the smallest acoustic impedance with $0.00041 \times 10^{6} \mathrm{~kg} / \mathrm{m}^{2} \mathrm{~s}$ compare to other materials. All materials showed greater than 0.95 for correlation coefficient and proved that the ultrasonic sensor can detect the foreign objects.

\section{CONCLUSION}

This paper presents the modelling and experimental work to investigate the linearity of ultrasonic sensor for detecting the foreign body in milk product. The modelling comprises of two parameters which are acoustic impedance and amplitude wave. The lowest transmission coefficient was shown when the ultrasonic wave propagated from milk to air medium with $0.10 \%$, followed by steel material with $13.20 \%$ and rubber 
with $99.23 \%$. The linear model for amplitude wave was calculated and the results for both theoretical and experimental plots has been obtained. This research shows that the ultrasonic sensor can determine the materials and size of foreign body contain inside the milk cartons using non-destructive method and beneficial in the field of food safety and quality assurance.

\section{ACKNOWLEDGEMENTS}

The authors would like to acknowledge the assistance of Universiti Teknologi Malaysia for providing the financial support and infrastructure which allowed this project to be implemented successfully.

\section{REFERENCES}

[1] S. Salo and G. Wirtanen,"Ultrasonic Cleaning Applications in Dairies - Case Studies on Cheese Moulds and Milk Transportation Crates", Food Journal vol. 109, pp. 31-42, 2007.

[2] M.C.Edwards and M.F. Stringer,"Observations on Patterns in Foreign Material Investigations"Food Control, vol. 18, pp. 773-782, 2007.

[3] A. Mulet, J. Benedito, Y. Golás and J. Cárcel, "Noninvasive Ultrasonic Measurements in the Food Industry", Food Review International,. vol. 18, pp. 123-133, 2002.

[4] J. Chandrapala and T. Leong,"Ultrasonic Processing for Dairy Applications: Recent Advances"Food Engineering Review,vol. 7, pp. 143-158, 2015.

[5] S. Kentish and H. Feng,"Applications of Power Ultrasound in Food Processing"Annual Review Food Science Technologyvol. 5, pp. 263-284, 2014.

[6] L. Zheng and D.W. Sun,"Innovative Applications of Power Ultrasound During Food Freezing Processes - A Review"Trends Food Science Technology, vol. 17, pp. 16-23, 2006.

[7] D.M. Sango, D. Abela, A. Mcelhatton and V.P. Valdramidis,"Assisted Ultrasound Applications for The Production of Safe Foods"Journal Applied Microbiology, vol. 116, pp. 1067-1083, 2014.

[8] L.R. Correia, G.S. Mittal and O.A. Basir,"Ultrasonic Detection of Bone Fragment in Mechanically Deboned Chicken Breasts"Innovative Food Science Emerging Technology, vol.9, pp. 109-115, 2008.

[9] B. Zhao, O.A. Basir and G.S. Mittal,"Detection of Occluded Small Objects in Glass Bottles Filled With Beverages via Ultrasound Center Frequency Tracing"LWT - Food Science Technology, vol. 42, pp.162-167, 2009.

[10] P. Pallav, D.A. Hutchins and T.H. Gan,"Air-Coupled Ultrasonic Evaluation of Food Materials". Ultrasonicsvol. 49, pp. 244-253, 2009.

[11] V. Leemans and M.F. Destain,"Ultrasonic Internal Defect Detection in Cheese"J.ournalof Food Engineering. vol. 90, pp. 333-340, 2009.

[12] M.D. Tantray, A. Rather, Q. Manaan, I. Andleeb, M. Mohammad and Y. Gull,." Role of Ultrasound in Detection of Radiolucent Foreign Bodies in Extremities".Strategies Trauma Limb Reconstr.vol. 13.pp. 81-85, 2018.

[13] B. Polat, Y. Atici, T. Gurpinar, A.E.Polat, D. Karaguven andí.T.Benli, "Diagnosis and Treatment of Retained Wooden Foreign Bodies", Acta Ortop Bras.vol. 26, pp. 198-200, 2018.

[14] D.J. Mcclements and G. Sundaram,"Ultrasonic Characterization of Foods and Drinks : Principles, Methods and Applications", Critical Review in Food Science and Nutritionvol. 37. pp. 1-46, 1997.

[15] K. R. Hasslerand and K. Homayoon, "A Novel Technique for Removal of Urogenital Magnetic Foreign Bodies", Open Journal of Urology, 8, pp. 223-227, 2018.

[16] J. Le Coz, S. Orlandini,L. Titomanlio and V. E. Rinaldi, "Point of care ultrasonography in the pediatric emergency department", Italian Journal of Pediatrics44, pp. 1-8, 2018.

[17] D. Iuliano, M. Mauro, N. Migliore, P. Dattolo, G. Migliore, B. Mauro, M. E. Bottiglieri, A. Tiso, C. Russo and C. Napolitano,An Unusual Acute Pancreatitis due to a Migrated Foreign Body",J Clin Case Rep, 8, pp 1-3, 2018.

[18] R.F. Liu,T. Kuoand Y. Chao, "Alopecia with foreign body granulomas induced by Radiesse injection: A case report", Journal of Cosmetic and Laser Therapy 20, pp. 462-464, 2018.

[19] F. Liaw, O. Murray, Y. Y. Tan and T. Hems, "Retained Foreign Body in a Diabetic Patient's Hand", The Open Orthopaedics Journal, 12, pp. 203 - 207, 2018.

[20] O.A. Makinde, O.O.Adebayo, A.A.Adeniyi and R.A.Ajadi, "Jejunal linear foreign body obstruction in a three year old female Boerboel", Sokoto Journal of Veterinary Sciences, 16, pp. 87 - 91, 2018.

[21] G. B. Holmes, A. Bitterman, A. R. Hsu, J. S. Sclamberg and S. Gitelis, "Intraoperative Ultrasound Guidance for the Removal of Nonmetallic Foreign Body from the Foot: Case Report", Foot \& Ankle Specialist, 10, pp. 82-85, 2017.

[22] M.N.B. Melo, L. N. Pantoja,S. J.A. Vasconcellos,V. A. Sarmento and C. S. Queiroz, "Traumatic Foreign Body into the Face: Case Report and Literature Review", Case Reports in Dentistry, pp. 1-5, 2017.

[23] T. Khan, M. Alam, K. Kadir, Z. Shahid, M.S. Mazliham, S. Khan and M.Miqdad, "Recognizing Foreign Object Debris (FOD): False Alarm Reduction Implementation",Indonesian Journal of Electrical Engineering and Computer Science 11, pp. 41 46, 2018.

[24] A.R. Prabhakar, V.N. Saraswathi and T.G. Manjunath, "Staple and Wooden Diet: Foreign Bodies in a Traumatised Tooth with Periapical Pathology", Austin J Dent. 4, pp. 1070-1075, 2017.

[25] F. G. Rodrigues, J. B. Campos, G. DaSilva and S. D. Wexner, "Endoscopic Ultrasound in the Diagnosis of Foreign Bodies of the Colon and Rectum", Rev Assoc Med Bras, pp. 818-821, 2016. 
[26] D.Franchini, C. Valastro, S.Ciccarelli, F.Caprio, D.Lenoci, and A. D. Bello, "Ultrasonographic Detection of Ingested Fishing Lines in Lloggerheads (CarettaCaretta).Journal of Wildlife Diseases 54, pp. 680-690, 2018.

[27] A. N. Pandey, "Ocular Foreign Bodies: A Review", Journal of Clinical \& Experimental Ophthalmology, 8, pp. 1-5, 2017.

[28] Z. Aftab, S. M. Ali, S.Koliyadan and 1 Al-Kindi, "Foreign body in the liver: Case report and review of literature",Qatar Medical Journal, 1, pp. 1-5, 2015.

[29] S. Gounder and J, Tan, "Laparoscopic Retrieval of Intra-Abdominal Foreign Bodies", Juniper Online Journal of Case Studies, 2, pp. 1-4, 2017.

[30] A. Sadaka, T. Prager, H. Beaver and A. Malik, "A novel use of ultrasound biomicroscopy", Eye, 32, pp. 474-475, 2018.

[31] O. Fasina, M. O. Ugalahi, O. T. Oluwaseyi and C. O. Bekibele, "Unusual intraorbital foreign bodies: A report of two cases and review of literature", African Journal of Trauma, 6, pp. 19-22. 2017.

[32] U. Khan, S. Shahrukh,T. B. Khalid, A. S. Memon and J. Ahmad, "Odyssey of an Accidently Ingested Sewing Needle From Mouth to Mesentery of Small Bowel in A Young Female", Journal of Pakistan Medical Association, 68, pp. 1418-1420, 2018.

[33] M. A. Mitev, S. Valkanov, V. Ribarova and B. Parvanova, "Suitability of The Modality Virtual Bronchoscopy with Aspiration of a Foreign Body", Trakia Journal of Sciences, 3, pp 224-232, 2018.

[34] C. Roux, F.J. Venter and R.M. Kirberger, "Cervical Porcupine Quill Foreign Body Involving The Spinal Cord of a Dog: A Descripton of Various Imaging Modality Findings", Journal of the South African Veterinary Associaton, pp. 1-7. 2017.

[35] G. Nakib, V. Calcaterra and G. Pelizzo, "Longstanding Presence of a Vaginal Foreign Body (Battery): Severe Stenosis in a 13-Year-Old Girl", J Pediatr Adolesc Gynecol 30, pp. 15-18, 2017.

[36] K. Rathore, "Endodontic management of foreign body in root canal of 10 year child: a case report", Saudi J. Oral.Dent. Res. 2, pp. 163-167, 2017.

[37] J. Singleton, J. M. Schafer, J. S. Hinson, S. Hinson, E.M. Kane, S. Wright, and B. Hoffmann, "Bedside Sonography for the Diagnosis of Esophageal Food Impaction", American Journal of Emergency Medicine, 35, pp. 720-724, 2017.

[38] C. Mahesh, D. Animireddy, S. Mettu and M. Kulkarni, "An Unexpected Encounter with Foreign Body in the Primary Teeth and Its Management", International Journal of Applied Basic Medical Research, 8, pp.181-183, 2018.

[39] E. E. V. Ezenwa, E. O. Osaigbovon and I.J. Ofuani, "Unusual Intravesical Foreign Body Following Perineo-vesical Injury", Nigerian Journal of Surgery, 24 pp. 44-47, 2018.

[40] T. Natung, W. Shullai, D. Lynser and T. Tripathy, "A Challenging Case of A Large Intraorbital Foreign Body Perforating The Nasal Septum in a Child", Indian Journal of Ophthalmology, 66, pp. 1511-1513, 2018.

[41] A. Mustapha, O. M. Olajide, R. M. Aliyu and B. A. O Kolawole, "Palm Fronds and Animal Jaw in the Vagina Mimicking Advanced Cancer of the Cervix", Sub-Saharan African Journal of Medicine, 5, pp. 32-35, 2018.

[42] Khairi, M.T.M., Ibrahim, S., Yunus, M.A.M. and Faramarzi, M. "Ultrasonic tomography for detecting foreign objects in refrigerated milk cartons", International Journal of Dairy Technology, 70, pp. 1-7, 2018.

\section{BIOGRAPHIES OF AUTHORS}

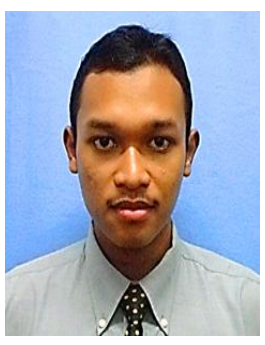

Mohd Taufiq Mohd Khairi received the B.Eng. and M.Eng degree in Engineering (Electrical) from Universiti Teknologi Malaysia in 2011 and 2014, respectively. He is currently furthering his study in Ph.D degree at the same institution under Control and Mechatronic Engineering Department, School of Electrical Engineering. His current research interest includes process tomography, sensing technology and food engineering.

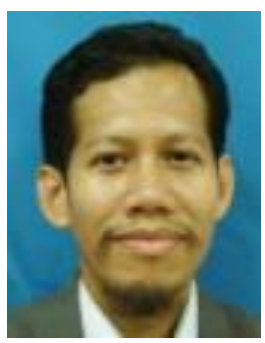

Sallehuddin Ibrahim received the Ph.D. degree in process tomography from Sheffield Hallam University, Sheffield, U.K., in 2001. He is currently an Associate Professor with the Control and Mechatronics Engineering Division, School of Electrical Engineering, Universiti Teknologi Malaysia, Skudai, Malaysia. He has published several papers in various journals and has presented papers in various conferences. His current research interests include instrumentation, sensors, tomography and ultrasound.. 


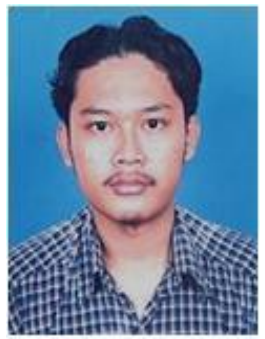

Mohd Amri Md Yunus received the B.Eng. degree (honors) in electrical control and instrumentation and the M.Eng. degree in electrical engineering from Universiti Teknologi Malaysia, Skudai, Malaysia, in 2002 and 2005, respectively, and the Ph.D. degree in electrical engineering from the School of Engineering and Advanced Technology, Massey University, Palmerston North, New Zealand, in 2011. His dissertation is entitled "Planar electromagnetic sensors for environmental monitoring." He joined the School of Electrical Engineering, Universiti Teknologi Malaysia, as a Lecturer in 2006. His current research interests include process tomography, planar electromagnetic sensors, and sensing technology.

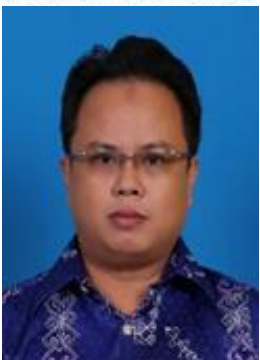

Ahmad Ridhwan Wahap was born in 1973 in Miri, Sarawak, Malaysia. He received the Bachelor of Electrical Engineering (Mechatronics) in 1998 and Master of Engineering (Electrical) from Universiti Teknologi Malaysia, Malaysia in 1998 and 2002 respectively. Currently he is a lecturer in the School of Electrical Engineering, Universiti Teklonologi Malaysia, Malaysia. His research interest are machine vision, image processing, and artificial intelligence. 